\title{
Occurrence of Gastrointestinal Parasitic Associated with Exotic Dogs in Commercial Breeding Mills in Jos Metropolis-Nigeria
}

\author{
Amapu T. Y.* \\ Department of Science Laboratory Technology, University of Jos, Nigeria
}

Latu M. Y.

Department of Animal Health and Production, College of Agriculture Garkawa, Plateau state

Dapiya H. S.

Department of Microbiology, University of Jos, Nigeria

Pam K. V.

Department of Microbiology, University of Jos, Nigeria

Job M. O.

Department of Science Laboratory Technology, University of Jos, Nigeria

Dawen D. E.

Department of Plant Science and Technology, University of Jos, Nigeria

Brengshak S. B.

Federal College of Animal Health and Production Technology, NVRI Vom, Nigeria

Ajang Y.

Department of Microbiology, University of Jos, Nigeria

Hero G. U.

Department of Microbiology, University of Jos, Nigeria

Dingmun P. J.

Department of Microbiology, University of Jos, Nigeria

Okojokwu O. J.

Department of Microbiology, University of Jos, Nigeria

\begin{abstract}
In Nigeria, there has been an increasing trend towards establishing puppy mills for commercial breeding of exotic dogs. This study determined gastrointestinal parasites associated with exotic dogs of the existing puppy mills in Jos Metropolis Nigeria. A total of 150 dogs' fresh feacal samples were collected from 25 different puppy mills and examined using formol ether and floatation concentration techniques. Data on risks factors variables of dogs' age, number of dogs per kernel kennel type, nature of food and history of antiparasitic drugs usage were collected from the breeders using predesigned questionnaire. The result revealed an overall prevalence of $71.33 \%$ intestinal parasitic burden among the dogs. Chi square $(\chi 2)$ analysis showed association $(\mathrm{p}<0.05)$ between breeds of dogs and occurrence of parasites. The gastrointestinal parasites associated were most prevalent dogs in Neapolitan mastiff $(86.36 \%)$ followed by Rottweiler $(75.70 \%)$ and German Shepherd $(57.14 \%)$ was the least infected Predominantly, a total of seven (7) species of intestinal parasites; Ancylostoma caninum (28.00\%) Dipylidium caninum (23.33\%), Toxocara canis (14.00\%), Trichuris vulpis (11.33\%), Taenia sp. (5.33\%) Giardia sp. (7.33\%) and Coccidia sp. $(5.33 \%)$ were identified. Among different gastrointestinal parasitic infections, occurrence of Ancylostoma caninum $(28.00 \%)$ was highest, followed by Dipylidium caninum (23.33\%). Multiple parasitic infections among positive dogs sampled were observed, however, risk factors variables did not $(\mathrm{p}>0.05)$ affect parasitic infection. Age based gastrointestinal parasitic infection peak (77.78\%) was reported among 79 months old and decreased with ages of dogs The result showed no significant difference in prevalence of gastrointestinal parasites among age groups of the $\operatorname{dogs}(\chi 2=2.616$, d.f. $=5, \mathrm{P}=0.624)$. This trend implies that puppies of younger age groups had higher prevalence and tendency for infection with gastrointestinal parasites than their older counterparts. This study provides baseline data on the spectrum of intestinal parasitic infection of exotic dogs in commercial puppy mills in Jos-Nigeria. Therefore, the phenomenon could represent an important health threat and needs to be regulated, so that breeders adhere to hygiene practices and veterinary guidelines. This will serve as an approach to reduce the tendency of
\end{abstract}


increasing intestinal parasitic burden of local dogs as well as eliminate emergent zoonotic intestinal parasites in the dogs.

Keywords: Exotic dogs; Gastrointestinal parasites; Puppy breeding mills; Risk factors; Jos.

(a) (1) CC BY: Creative Commons Attribution License 4.0

\section{Introduction}

Dogs are the most adapted canids close to humans, with intent for security, companionship, and psycho-social purposes. In spite of these benefits, dogs remained a reservoir of many infective stages of intestinal parasites [1-3], Predominantly, dogs are definitive hosts for more than 60 gastrointestinal zoonotic parasites with; Strongyloides stercoralis, Ancylostoma caninum, Dipylidium caninum, Toxocara canis, Echinococcus granulosus and Trichuris vulpis as the most common [4], Among local dogs, Toxocara canis, Strongyloides stercoralis, Ancylostoma caninum, Ancylostoma braziliense, Necatus americanus, Isospora canis and Uncinaria stenocephala have been reported in Nigeria [5, 6], Commonly, these gastrointestinal parasitic are the causes of most clinical signs and mortality in dogs $[7,8]$. Similarly, in communities where animal management husbandry is lacking, gastrointestinal parasites could also be the major threats to public health [9].

In Nigeria, ownership of foreign breeds of dogs has recently become a passion that residents could spend whatever is necessary to have a dog with pride. This has recently stimulated dog breeding mills; a facility that profits from selling puppies on a large scale in Nigeria [10], However, the husbandry practice requires migration of dogs from developed countries to be bred indigenously. Incidentally, global animal trade had been identified as a network central to the spread of infectious diseases in animal populations [11], Of great concern, is the associated risk of introducing exotic zoonotic parasitic to domestic animals and humans [12, 13], since these exotic animals could be carriers of zoonotic diseases of the importing countries [11].

In Nigeria, adequate tracking data for the list of all different parasitic diseases, and health regulations carried on animals is still being advocated by co workers [14], As a result, it is not easy to ascertain strict compliance to regulation and controls particularly during importation of these exotic dogs. More so that most of these breeders have little knowledge of good animal husbandry practices. In most communities, these breeding mills are indiscriminately sited even within human habitations with the dogs housed in makeshift shelters or kennels. It is also apparent the disregard to hygiene and sanitation practices, proper feaces, urine, and carcasses disposal by most puppy mills owners by our preliminary observations. This poor animal husbandry leaves no doubt on their lack of regulation by authorities concern. Therefore, this research was carried out to provide baseline data on the prevalence and potential risk factors associated with gastrointestinal parasitic infestation among the dogs in commercial puppy mills in Jos.

\section{Materials and Methods}

\subsection{Study Area}

The study was conducted in tropical climate that falls within northern Guinea Savannah vegetation zone of subSaharan African. Plateau State is located in the middle belt of Nigeria and forms a highland area standing between latitude $8^{\circ} 30^{\prime}$ and $10^{\circ} 10^{\prime} \mathrm{N}$ and longitudes $8^{\circ} 20^{\prime}$ and $9^{\circ} 30^{\prime} \mathrm{E}$ [15], The study area is characterized by tropical wet and dry climate with long-term mean annual rainfall of $1300 \mathrm{~mm}$ (1008.6 to $2184.70 \mathrm{~mm}$ ) lasting from March to November. It has a near temperate climate with an average annual temperature of between 13 and $22^{\circ} \mathrm{C}$ that have supported a large population of domestic and exotic dogs breeding activities.

\subsection{Study Design}

A cross-sectional study was carried out to evaluate the prevalence of gastrointestinal parasites among dogs in commercial puppy mills. The metropolis was clustered into 7 major settlements of Apata, Alheri, Busa-Buji, Utan, West of Mines, Bukuru and Rayfield in Jos metropolis were selected due to availability of the puppy mills. A total of 150 fresh faecal samples were randomly collected from 25 privately-owned exotic dog breeding mills between May and November 2015. At each mill, six dogs were also randomly selected based on the willingness of mill staff to participate. The animals were then categorized by age group into; 0-3, 4-7, 8-11, 12-15 and > 16-months-old. Analyses of risk factors such as gender, species of dog, type of food, housing conditions (singled housing/grouped housing) and duration of antiparasitic treatment in relation to prevalence of parasites were then obtained using structured questionnaire.

\subsection{Ethical Aspects}

This study was not invasive to animals and sampling was carried out in accordance with good veterinary practice after obtaining consent from the owner of the breeding mills.

\subsection{Administration of Questionnaire}

Data that focused on dogs' age, sex of dog, species of dog, number of dogs per kennel, nature of food and antiparasitic drug usage preceding this study were collected using predesigned questionnaire.

\subsection{Collection of Samples}

A total of 150 fresh faecal samples were collected randomly from privately-owned dog breeding mills in Jos metropolis. In each puppy mill, early morning non-pooled freshly voided feacal samples were collected from top 
layers using a flame sterilized spatula. The samples were then placed into cleaned universal containers containing $10 \%$ formalin and labeled with dog number corresponding to owner's name and place of collection. All the faecal samples were then transported immediately to Department of Microbiology laboratory University of Jos for analysis.

\subsection{Parasitological Analyses}

Parasitological assessment of faecal samples was carried out by physical examination for the present of adult worms or larvae. Microscopic examination was carried out using formal-ether sedimentation and sodium chloride floatation techniques following standard procedures. Parasites were identified in accordance with keys and characteristics described in the parasitological manual [16], The result was considered positive when at least parasite eggs or cysts were observed.

\subsection{Statistical Analysis}

The results obtained were evaluated using descriptive statistics to determine prevalence of dogs parasitized. Chi-squared test was used to determine the association between parasite prevalence with dogs' age, sex of dog, number of dogs per kennel, dog species type, kennel type, nature of food and antiparasitic drug usage age. Statistical tests were performed using SPSS version 23.0 for Windows ${ }^{\circledR}$ (SPSS Inc, Chicago, Illinois, USA) with significant correlations observed at $95 \%$ confidence level $(\mathrm{p}<0.05)$.

\section{Results}

Out of 150 faecal samples examined, findings of this study revealed that $71.33 \%(107 / 150)$ of the exotic dogs were positive for at least an eggs or cysts of gastrointestinal parasites (Table 1). Chi-Square $\left(\chi^{2}\right)$ analysis revealed variation $(\mathrm{p}<0.05)$ in infection prevalence of parasitic infection with breed of the dogs. The gastrointestinal parasites were most prevalent in dog Neapolitan mastiff $(86.36 \%)$ followed by Rottweiler $(75.70 \%)$ with German Shepherd (57.14\%) the least infected. Predominantly, seven (7) species of parasites; Ancylostoma caninum, Dipylidium Caninum, Toxocara canis, Trichuris vulpis, Taenia spp., Gairdia spp and Coccidia spp were associated with the feacal samples (Table 2). Species of A. caninum 42(28.00\%) were the most frequently detected, followed by $D$. caninum $35(23.33 \%)$ while Coccidia spp. 5(5.33\%) occurred least in the dogs. This data confirmed that polyparasitism is very common among the infested dogs although, did not differ $(p>0.05)$ among the breeds of dogs.

In relation to age of dogs (Table 3), gastrointestinal parasitic infestation peaked $(77.78 \%$ ) in 8-11 months old dogs, followed by dogs 4-7 months and least $>16$ months old age groups. However, no significant associations between prevalence of gastrointestinal parasitic infestation and age groups of dogs were observed $(\chi 2=2.616$, d.f. $=$ $5, P=0.624)$. This trend showed that puppies of younger age had higher prevalence and tendency for infection with gastrointestinal parasites. Distribution of predominant intestinal parasites based on age of dogs revealed that $A$. caninum had highest prevalence $(28.00 \%)$ followed by D. caninum $35(23.33 \%)$ while Coccidia spp. (3.33\%) were the least occurred. Relatively, A. caninum burdened was highest in puppies of 4-7 months (30.02\%) and followed by $0-3$ months $(32.42 \%)$ old puppies. Species of D. caninum were however reported prominent (33.33\%) in age group (8-11months). Taenia sp. (3.70\%) was the least occurred among the parasites in relation to the age of dogs. Multiple parasitic infections were observed among all the ages of dogs sampled. Relative distribution of parasites showed that, age group of 10 to 13 months only harbored four (4) species of the parasites. The seven detected parasites however, occurred concomitantly among puppies of lower (0-6months) age group

Prevalence of parasite infestation and risk factors variables associated with gastrointestinal infestation in kenneled dogs is presented in Table 4. The result showed no significant association $(\mathrm{P}>0.05)$ between risk factor variables and prevalence of parasites infestation. In this study, however, higher infection prevalence was observed in female than male dogs $(70.73 \%$ versus $42.06 \%, \mathrm{P}>0.005)$. This finding $(\mathrm{OR}=1.07 ; 95 \%$ CI: $0.52-2.18 ; P=0$. 0.858). This implies that female dogs may likely than their male counterparts $(72.06 \%$ versus $70.73 \%, P>0.05)$. Moreover, the parasitism among the dogs was not influenced by the nature of their food (OR1.0481 95\% CI 0.5163 to 2.1279$)$. Nonetheless, highest parasite infestation (71.80\%) was observed in dogs fed industrially manufactured foods compared to dogs on locally manufactured foods $(70.83 \%)$. In terms of housing, most of the dogs sampled were grouped. Dogs kernelled communally showed higher $(72.45 \%)$ prevalence of intestinal parasites compared to $(69.23 \%)$ those individually housed (OR $0.855695 \%$ CI. 0.4095 to 1.788 ).

In this study, the entire dog mills employed deworming as a common practice however; administration frequency of antihelmintic drugs was not observed to vary among the mills. Out of the 150dogs that received anthelmintics, only 43(28.67\%) were not infested. The trend showed lower parasitic infections in dogs recently received antihelminth drugs and increased with durations in last administration. It was observed that prevalence of parasitic infection occurred in 4 weeks $(78.48), 6$ weeks $(75.00 \%)$ and 2 weeks $(61.91 \%)$ in descending order of antiparasitic drug administration. However, this result revealed no significantly associated $(\chi 2=0.317, \mathrm{df}=5, P=$ 0.957 ) between duration of antiparasitic usage and parasitic infection in the dogs.

\section{Discussion}

This research revealed high prevalence and diversity of intestinal parasites infestation among exotic dogs in commercial breeding mills. Globally, dogs are known as definitive host for most gastrointestinal parasites [17]; [18, 19], Therefore, the high prevalence $(71.33 \%)$ of intestinal parasites infestations among exotic dogs is global problem and conformed with common reports such as $81.3 \%$ of helminths among exotic dogs in Bahir Dar, Ethiopia [20], 
76\% in South Africa [21], and 71\% in Cordoba, Spain [7]. However, lower rate of intestinal parasites infection among kenneled dogs have been reported in countries such as Australia (23.9\%), Spain (25\%) and 26\% Greece [22].

In Nigeria, only a few studies on the assessment of gastrointestinal parasites among exotic kenneled dogs have been carried out $[23,24]$, Commonly, these base line data revealed low prevalence such as $12.3 \%$ in Ibadan [25], in Jos $7.68 \%$ [23], and $11.4 \%$ in Enugu [26], Conversely, these researches were conducted among local dogs and comparatively few samples of exotic dogs which might have influenced the statistical power of the analysis. In most of the studies, a wide variation in prevalence of gastrointestinal parasites exists among the local dogs. In this study area however, a relatively lower prevalence 37\% [19], 66.10\% [27] were reported among local dogs. Many studies have although supported that kennel management had a significant influence on the prevalence of gastrointestinal parasite infections [28], and that kenneled dogs are unlikely to come in contact with infective stages of intestinal parasites. However, habit of keeping dogs in single compartment kennels where they defecate had been a significant factor in maintenance of a highly infective habitat [29], This is because house breaking habits among the confined dogs cannot be practiced resulting to soiling of their quarters as observed during this study among the dog mills. Alongside, keeping faeces of infected dogs in kennels of cluster population increases the risks for disease transmission for the infected dog as well as the population [30, 31], Therefore, low occurrence of intestinal parasites among the kenneled dogs with good hygiene and veterinary practices is expected.

In the examined samples, Ancylostoma caninum, Dipylidium caninum, Toxocara canis Trichuris vulpis, Taenia spp, Giardia spp and Coccidia spp were most common parasites associated with the exotic dogs. Predominantly, Oncocicola canis, Diphylobothnm latum, Ancylostoma caninium, Necatus americanus, Toxocara canis and Isospora cani had been reported as the most common associated parasites of dogs in the study area [6, 19, 23], The result of this study, suggests that the exotic dogs may be more susceptible to native strains of the intestinal parasites. Consequently, the occurrence of Trichuris vulpis, Taenia spp, Giardia spp, and Coccidia spp. in the exotic dogs is uncommon among the local breeds. The predominance of Ancylostoma caninum and Dipylidium caninum in exotic dogs is consistent with local [6], and foreign reports [32, 33], Ancylostoma caninum had been reported as widespread parasites in the study area and common parasitic forms in dogs [6, 19], Naturally, infective stages of Ancylostoma caninum contaminate and survived weeks with longevity reaching several years in hosts, responsible for the high colonization in dogs. Also, strains of Toxocara canis and Giardia duodenalis has emerged as one of the most prevalent parasitic infections reported in kenneled dogs worldwide [24, 34, 35].

Mixed parasitism reported among the exotic dogs is a reflection of high gastrointestinal parasites prevalence. Although multiple parasitisms are common however, a number of mixed parasites in this study are higher than results obtained previously among local dogs in Jos North and South [27]. These differences could reflect higher susceptibility of the exotic dogs to intestinal parasites observed in our setting. Although, multiple parasitisms are commonly ascribed to improper kennel hygiene and food handling practices [36], biological factors are suspected to drive the affinity and influencing parasites co-existence [37], Therefore, this complexity suggests that control efforts towards reduction of parasites infestation should be directed to the use of combination antiparasitic drugs to avoid outbreak in other animals or humans.

Considerably, analysis of risk factors such as host age, breed and gender of dog, living conditions, anthelmintic treatments and feed types are important variables reported influencing parasites infections in dogs [28, 38]. In this study susceptible to acquiring GIT parasites is higher in younger dogs. Consistent with previous findings, puppies are more likely to be infected and this literally decreased with age [7, 33, 39, 40], Many factors could be attributed to this trend, however transplacental and transmammary routes transmission pattern of parasites such as ascarid in the first few days of puppy's life have been acknowledged [24], The acquired age-dependent immunity by adult dogs as well as the fecundity of the parasite, probably as consequence of repeated exposure is commonly recognized to reduce gastrointestinal parasites infections [24], Since Puppies are immuno incompetence, they could be more susceptible to parasitic infestation as earlier suggested [24, 38].

Contrary to the finding of this study, sex of host animals had been reported to significantly influenced prevalence of gastrointestinal parasites [24], In few studies, female dogs are likely to contract intestinal parasites than male dogs $[23,26]$, This had been linked to the physiological peculiarities of female dogs that constitute stress factors and thus reduce their immunity to infections [24],

Commonly, feed brands are risk factor reported to be associated with occurrence of gastrointestinal parasites in dogs [20]. In this study, no association of gastrointestinal parasites with feed brands has been established. The poor handling and hygiene practices could result in traverse contamination of either the local made or industrial dog foods.

Despite levels of antiparasitic usage, most of the dogs examined in this study were infested with multiple parasites. Our finding indicates that anthelmintics irregularly administered and had limited effect on the prevalence of parasites infestation among the sampled dogs. An epidemiological assessment in Mexico had shown that dogs with history of deworming were all infected with spectrum of intestinal parasites [18], Similarly, effects of antihelminthics are shown not to always influence the prevalence of helminthes in dogs [1], [41]. As observed, anthelmintic treatment with an average of 2-3 per year was not sufficient in controlling parasitism efficiently in dogs in agreement with the report of Kostopoulou, et al. [42], Therefore, conformance with the general recommendation by European Scientific Counsel Companion Animal Parasites [43], guidelines for treatment frequency of at least 4 times per year is expected for worm control in dogs. This observation calls for an effective antiparasite control program and improve hygiene practices of kennels in order to minimize the risk of exposure of canine to parasites infestation. 


\section{Conclusion}

The present study revealed high prevalence of gastrointestinal parasites among exotic dogs in Jos metropolis than reported cases among the local dogs. In this study, multiple parasitisms were more common and most of the parasites identified were of zoonotic concerns. However, most of the risk factors variables showed no significant association with intestinal parasitic infestation among the dogs. This suggests that the predisposing factors are common and management is deficient in rigorous quarantine or hygiene protocols in the breeding kennels.

From the result of this study, it becomes eminent to urgently regulate the practice of commercial dog breeding mills in Jos. This is necessary so as to ensure that breeders adapt to good management practices and veterinary guidelines that will eliminate high zoonotic parasites among the dogs

\subsection{Conflict of Interests}

The authors declare that there was no conflict of interests regarding the publication of this paper.

Table-1. Prevalence of Gastrointestinal Parasites in Exotic Breed of Dogs in breeding mills in Jos

\begin{tabular}{l|l|l|l|l|l}
\hline Breed of Dogs & No. Examined & No. Infected & Prevalence $(\%)$ & $\chi^{2}$ & P-value \\
\hline Rottweiler & 33 & 25 & 75.76 & 5.98 & $<0.0001^{* *}$ \\
\hline Bullmastiff & 17 & 11 & 64.71 & & \\
\hline Caucasian & 34 & 24 & 70.59 & & \\
\hline German Shepherd & 28 & 16 & 57.14 & & \\
\hline Neapolitan Mastiff & 22 & 19 & 86.36 & & \\
\hline Pit Bull & 16 & 12 & 75.00 & & \\
\hline Total & 150 & 107 & 71.33 & & \\
\hline
\end{tabular}

Table-2. Occurrence of gastrointestinal parasites in relation to breed of exotic dogs in puppy mills in Jos

\begin{tabular}{|c|c|c|c|c|c|c|c|}
\hline Breed of Dog & \multicolumn{6}{|c|}{ Parasites /Frequency $(\%)$ of Occurrence } & \\
\hline & A. caninum & D. caninum & T. canis & T. vulpis & Taenia spp. & G. duodenalis & Coccidia spp. \\
\hline Rottweiler & $10(30.30)$ & $8(24.24)$ & $6(18.18)$ & $4(12.12)$ & $0(0.00)$ & $2(6.06)$ & $1(3.03)$ \\
\hline Bullmastiff & $5(29.41)$ & $2(11.76)$ & $3(17.65)$ & $3(17.65)$ & $2(11.76)$ & $1(5.88)$ & $0(0.00)$ \\
\hline Caucasian & $8(23.53)$ & $9(26.47)$ & $4(11.76)$ & $2(5.88)$ & $1(2.94)$ & $2(5.88)$ & $3(8.82)$ \\
\hline $\begin{array}{l}\text { German } \\
\text { Shepherd }\end{array}$ & $6(2.43)$ & $7(25.00)$ & $4(14.29)$ & $3(10.71)$ & $3(10.71)$ & $1(3.57)$ & $0(0.00)$ \\
\hline $\begin{array}{l}\text { Neapolitan } \\
\text { Mastiff }\end{array}$ & $7(31.81)$ & $6(27.27)$ & $1(4.55)$ & $3(13.64)$ & $0(0.00)$ & $4(18.18)$ & $1(4.55)$ \\
\hline Pit Bull & $6(37.50)$ & $3(18.75)$ & $3(18.75)$ & $2(12,50)$ & $2(12,50)$ & $1(6.25)$ & $0(0.00)$ \\
\hline Total & $42(28.00)$ & $35(23.33)$ & $21(14.00)$ & $17(11.33)$ & $8(5.33)$ & $11(7.33)$ & $5(3.33)$ \\
\hline$\chi^{2}$ & 1.916 & 1.987 & 2.743 & 1.849 & 8.110 & 4.658 & 5.394 \\
\hline P-value & 0.861 & 0.851 & 0.739 & 0.870 & 0.150 & 0.459 & 0.370 \\
\hline
\end{tabular}

$\mathrm{P}$-value $\leq 0.05$ is considered statistically significant. $\mathrm{n}=$ no positive (frequency $\%$ )

Table-3. Occurrence of gastrointestinal parasites in relation to age of exotic dogs in puppy mills in Jos

\begin{tabular}{|c|c|c|c|c|c|c|c|c|c|}
\hline \multirow{2}{*}{$\begin{array}{l}\text { Age } \\
\text { (months) } \\
\text { of Dog } \\
\end{array}$} & \multirow{2}{*}{$\begin{array}{l}\text { No. of } \\
\text { Dogs } \\
\text { Examined }\end{array}$} & \multirow{2}{*}{$\begin{array}{l}\text { No. } \\
\text { infected } \\
(\%) \\
\end{array}$} & \multicolumn{5}{|c|}{ Parasites /Frequency (\%) of occurrence } & \multirow[b]{2}{*}{$\begin{array}{l}\text { G. } \\
\text { duodenalis }\end{array}$} & \multirow[b]{2}{*}{$\begin{array}{l}\text { Coccidi } \\
a \text { sp. }\end{array}$} \\
\hline & & & $\begin{array}{l}\text { A. } \\
\text { caninum }\end{array}$ & $\begin{array}{l}\text { D. } \\
\text { caninum }\end{array}$ & T. canis & T. vulpis & $\begin{array}{l}\text { Taenia } \\
\text { sp. }\end{array}$ & & \\
\hline $0-3$ & 37 & $27(72.97)$ & $12(32.42)$ & $11(29.73)$ & $5(13.51)$ & $7(19.92)$ & $2(5.41)$ & $2(5.41)$ & $1(2.70)$ \\
\hline $4-7$ & 41 & $31(75.61)$ & $16(39.02)$ & $8(19.51)$ & $9(21.95)$ & $6(14.63)$ & $3(7.32)$ & $5(12.20)$ & $4(9.76)$ \\
\hline $8-11$ & 27 & $21(77.78)$ & $7(25.93)$ & $9(33.33)$ & $6(22.22)$ & $4(14.81)$ & $2(7.41)$ & $4(14.81)$ & $0(0.00)$ \\
\hline $12-15$ & 23 & $16(69.57)$ & $5(21.74)$ & $5(21.74)$ & $0(0.00)$ & $0(0.00)$ & $1(4.35)$ & $0(0.00)$ & $0(0.00)$ \\
\hline$\geq 16$ & 22 & $12(54.55)$ & $2(9.09)$ & $2(9.09)$ & $1(4.55)$ & $0(0.00)$ & $0(0.00)$ & $0(0.00)$ & $0(0.00)$ \\
\hline Total & 150 & $107(71.33)$ & $42(28.00)$ & $35(23.33)$ & $21(14.00)$ & $17(11.33)$ & $8(5.33)$ & $11(7.33)$ & $5(3.33)$ \\
\hline$\chi^{2}$ & & 2.616 & 7.239 & 5.218 & 9.054 & 8.641 & 1.834 & 7.414 & 7.777 \\
\hline P-value & & 0.624 & 0.124 & 0.266 & 0.060 & 0.071 & 0.766 & 0.116 & 0.100 \\
\hline
\end{tabular}

$\mathrm{P}$-value $\leq 0.05$ is considered statistically significant. 
Table-4. Occurrence of gastrointestinal parasites in relation to risk factors among exotic dogs in puppy mills in Jos

\begin{tabular}{|c|c|c|c|c|c|c|}
\hline Risk Factors & 21 & $\begin{array}{l}\text { No. of dogs } \\
\text { Examined }\end{array}$ & $\begin{array}{l}\text { No. of dogs } \\
\text { Positive }\end{array}$ & $\%$ Occurrence & $\chi^{2}$ & P-value \\
\hline \multirow[t]{2}{*}{ Sex } & Male & 68 & 49 & 72.06 & \multirow[t]{2}{*}{0.0986} & \multirow[t]{2}{*}{0.7535} \\
\hline & Female & 82 & 58 & 70.73 & & \\
\hline \multirow[t]{4}{*}{ Feed Brand } & & & & & \multirow[t]{4}{*}{0.1819} & \multirow[t]{4}{*}{0.9131} \\
\hline & $\begin{array}{l}\text { Local dog } \\
\text { food }\end{array}$ & 78 & 56 & 71.79 & & \\
\hline & $\begin{array}{l}\text { Industrial } \\
\text { dog food }\end{array}$ & 72 & 51 & 70.83 & & \\
\hline & $\begin{array}{l}\text { Mixed food } \\
\text { brand }\end{array}$ & 0 & 0 & 0.00 & & \\
\hline \multirow[t]{2}{*}{$\begin{array}{l}\text { Housing of } \\
\text { dogs per kennel }\end{array}$} & $\begin{array}{l}\text { Individual } \\
\text { housing }\end{array}$ & 52 & 36 & 69.23 & \multirow[t]{2}{*}{0.1748} & \multirow[t]{2}{*}{0.6759} \\
\hline & $\begin{array}{l}\text { Group- } \\
\text { housing }\end{array}$ & 98 & 71 & 72.45 & & \\
\hline \multirow{4}{*}{$\begin{array}{l}\text { Duration on } \\
\text { Anti-parasitic } \\
\text { Treatment }\end{array}$} & 2 weeks & 63 & 39 & 61.91 & \multirow[t]{4}{*}{0.3156} & \multirow[t]{4}{*}{0.9571} \\
\hline & 4 weeks & 79 & 62 & 78.48 & & \\
\hline & 6 weeks & 8 & 6 & 75.00 & & \\
\hline & 1 year & 0 & 0 & 0.00 & & \\
\hline
\end{tabular}

\section{References}

[1] Traub, R. J., Robertson, I. D., Irwin, P. J., Mencke, N., and Thompson, R. C., 2005. "Canine gastrointestinal parasitic zoonoses in India." Trends Parasitol, vol. 21, pp. 42-48.

[2] Gracenea, M., Gomez, M. S., and Torres, J., 2009. "Prevalence of intestinal parasites in shelter dogs and cats in the metropolitan area of Barcelona (Spain)." Acta Parasitology, vol. 54, pp. 73-77.

[3] Bartosik, J., Dziwirek, K., ojek, J., Kaczyk, J., and Górski, P., 2017. "Prevalence of intestinal parasite infection in dogs from selected rural areas of central and southern Poland." Scientific Annals of Polish Society of Animal Production, vol. 13, pp. 61-69.

[4] Paulos, D., Addis, M., Fromsa, A., and Mekibib, B., 2012. "Prevalence of gastrointestinal helminthes among dogs and owners perception about zoonotic dog parasites in Hawassa Town." Ethiopia. Journal of Public Epidemiology, vol. 4, pp. 205-209.

[5] Stregowski, J., 2007. "Zoonotic helminths from pets and wild life. A practical review and common intestinal parasites of dogs." pp. 78-81.

[6] Ogbu, K. I., Olaolu, O. S., Ochai, S. O., Maimadu, A. A., Olabode, M. P., and Poyi, N. L., 2018. "Prevalence of gastrointestinal zoonotic parasites of dogs in jos metropolis." World Journal of Pharmaceutical and Medical Research, vol. 4, pp. 22-26.

[7] Martinez-Moreno, F. J., Hernandez, S., Lopez-Cobos, E., Becerra, C., Acosta, I., and Martinez-Moreno, A., 2007. "Estimation of canine intestinal parasites in Cordoba (Spain) and their risk to public health." Veterinary Parasitology vol. 143, pp. 7-13.

[8] Brownman, D. D., 2009. Georgisiparasitology for veterinarians. 9th ed ed. WB Saunder Elsevier St. Louis, p. 45.

[9] Lowenstein, C., Waters, W. F., Roess, A., Leibler, J. H., and Graham, J. P., 2016. "Animal husbandry practices and perceptions of zoonotic infectious disease risks among livestock keepers in a rural parish of quito, ecuador." The American Journal of Tropical Medicine and Hygiene, vol. 95, pp. 1450-1458.

[10] Ishola, O. O., Awosanya, E. J., and Adeniyi, I. S., 2016. "Management and socio-economic determinants of profitability in dog breeding business in Oyo state, Nigeria." Sokoto Journal of Veterinary Sciences, vol. 14, pp. 32-39.

[11] Hartmut, H. K. L., Andreas, K., Hövel, P., Gethmann, J., Sauter-Louis, C., Selhorst, T., and Conraths, F. J., 2016. "Disease spread through animal movements: A static and temporal network analysis of pig trade in Germany." PLoS ONE, vol. 11, p. e01.

[12] Buofrate, D., Requena-Mendez, A., Angheben, A., Munoz, J., Gobbi, F., Van, D. E. J., and Bisoffi, Z., 2013. "Severe strongyloidiasis: a systematic review of case reports." BMC Infectious Diseases, vol. 13, p. 78.

[13] Villeneuve, A., Polley, L., Jenkins, E., Schurer, J., Gilleard, J., Kutz, S., Conboy, G., Benoit, D., Seewald, W., et al., 2015. "Parasite prevalence in fecal samples from shelter dogs and cats across the Canadian provinces." Parasites Vectors, vol. 8, p. e281.

[14] Atehmengo, N. L. and Nnagbo, C. S., 2014. "Emerging animal parasitic diseases: A global overview and appropriate strategies for their monitoring and surveillance in nigeria." The Open Microbiology Journal, vol. 8, pp. 87-94.

[15] Hill, I. D., 1978. "Land resources of central nigeria agricultural development possibilities." The Jos Plateau, Land Resources Development Centre, England, vol. 2B, pp. 14-16.

[16] Cheesbrough, M., 1990. Medical laboratory manual for tropical countries. 2nd ed ed. London, UK: HIV. supll:S P., pp. 2-23. 
[17] Mateus, T. L., Castro, A., Ribeiro, J. N., and Vieira-Pinto, M., 2014. "Multiple zoonotic parasites identified in dog feces collected in Ponte de Lima, Portugal - a potential threat to human health." International Journal of Environmental Research and Public Health, vol. 11, pp. 9050-9067.

[18] Alvarado-Esquivel., C., Romero-Salas, D., Aguilar-Domínguez, M., Cruz-Romero, A., Ibarra-Priego, N., and Pérez-de-León, Á. A., 2015. "Epidemiological assessment of intestinal parasitic infections in dogs at animal shelter in Veracruz, Mexico." Asian Pacific Journal of Tropical Biomedical, vol. 5, pp. 34-39.

[19] Pam, V. A., Ogbu, K. I., Akinyera, A. O., Gullek, J. F., and Okoro, J., 2015. "Investigation on the prevalence of gastrointestinal parasites in local and exotic dogs in Jos South Local Government Area of Plateau state, Nigeria." International Research Journal of Public and Environmental Health, vol. 2, pp. 5660.

[20] Zelalem, G. and Mekonnen, A., 2012. "Prevalence of gastrointestinal helminthes among dogs in Bahir Dar town, Ethiopia." World Applied Science Journal, vol. 19, pp. 595-601.

[21] Minnaar, W. N., Krecek, R. C., and Fourie, L. J., 2002. "Helminths in dogs from a peri-urban resource limited community in Free State Province South-Africa." Vet.erinary Parasitology, vol. 107, pp. 343-349.

[22] Jiménez-Cardoso, E., Eligio-García, L., Cortés-Campos, A., Estrada, A. C., Pinto-Sagahón, M., and Noguera-Estrada, C., 2010. "The frequency of intestinal parasites in puppies from Mexican kennels." Health, vol. 2, pp. 1316-1319.

[23] Pam, V. A., Lgeh, C. P., Hassan, A. A., Udokaninyene, A. D., Kemza, S. Y., Bata, S. I., Ogbu, K. I., and Daniel, L. N., 2013. "Prevalence of heamo and gastro intestinal parasites in dogs in Vom, Jos South Local Government, Plateau State." Journal of. Veterinary Medecine, vol. 33, pp. 74-78.

[24] Sowemimo, O. A. and Ayanniyi, O. A., 2017. "Gastrointestinal Helminth Parasites of Domestic Dogs in Ilesa, Osun State, Nigeria: A Faecal Examination Survey Study." Journal of Bacteriology and Parasitology, vol. 8, p. 311.

[25] Johnson, J. S., Hibler, C. P., Tillotson, K. M., and Mason, G. L., 2010. "Radiculomeningomyelitis due to Halicephalobus gingivalis in a horse." Veterinary Parasitology, vol. 38, pp. 559-561.

[26] Idika, I. K., Onuorah, E. C., Obi, C. F., Umeakuana, P. U., Nwosu, C. O., Onah, D. N., and Chiejina, S. N., 2017. "Prevalence of gastrointestinal helminth infections of dog in Enugu State, South Eastern Nigeria." Parasite Epidemiology and Control, vol. 2, pp. 97-104.

[27] Kutdang, E. T., Bukbuk, D. N., and Ajayi, J. A. A., 2010. "The Prevalence of Intestinal Helminths of Dogs (Canis familaris) in Jos, Plateau State, Nigeria." Researcher, vol. 2, pp. 51-56.

[28] Scaramozzino, P., Di Cave, D., Berrilli, F., D’Orazi, C., Spaziani, A., Mazzanti, S., Scholl, F., and De Liberato, C., 2009. "A study of the prevalence and genotypes of Giardia duodenalis infecting kennelled dogs." 182, vol. 182, pp. 231-234.

[29] Habluetzel, A., Traldi, G., Ruggieri, S., Attili, A. R., Scuppa, P., Marchetti, R., Menghini, G., and Esposito, F., 2003. "An estimation of toxocara canis prevalence in dogs, environmental egg contamination and risk of human infection in the Marche region of Italy." Veterinary Parasitology, vol. 113, pp. 243-252.

[30] Nijsse, R., Mughini-Gras, L., Wagenaar, J. A., and Ploeger, H. W., 2014. "Coprophagy in dogs interferes in the diagnosis of parasitic infections by faecal examination." Veterinary Parasitology, vol. 204, pp. 304-9.

[31] David, É. B., Guimarães, S., de Oliveira, A. P., Goulart, d. O.-S. T. C., Nogueira, B. G., Moraes, N. A. R., and Cacciò, S. M., 2015. "Molecular characterization of intestinal protozoa in two poor communities in the State of São Paulo, Brazil." Parasites and Vectors, vol. 8, p. 103.

[32] Dagmawi, P., Mekonnen, A., Abebe, F., and Berhanu, M., 2012. "Prevalence of gastrointestinal helminthes among dogs and owners perception about zoonotic dog parasites in Hawassa Town Ethiopia." Journal of Public Health Epidemiology, vol. 4, pp. 205-209.

[33] Urgel, M. F. M., Ybañez, R. H. D., and Ybañez, A. P., 2019. "The detection of gastrointestinal parasites in owned and shelter dogs in Cebu, Philippines." Veterinary World, vol. 12, pp. 372-376.

[34] Bowman, D. D., Montgomery, S. P., Zajac, A. M., Eberhard, M. L., and Kazacos, K. R., 2010. "Review Hookworms of dogs and cats as agents of cutaneous larva migrans." Trends Parasitol, vol. 26, pp. 162-7.

[35] Upjohn, M., Cobb, C., Monger, J., Geurden, T., Claerebout, E., and Fox, M., 2010. "Prevalence molecular typing and risk factor analysis for Giardia duodenalis infections in dogs in a central London rescue shelter." Veterinary Parasitology, vol. 172, pp. 341-346.

[36] Sowemimo, O. A. and Asaolu, S. O., 2008. "Epidemiology of intestinal helminth parasites of dogs in Ibadan, Nigeria." J. Helminthol, vol. 82, pp. 89-93.

[37] Kołodziej-Sobocińska, M., Demiaszkiewicz, A. W., Lachowicz, J., Borowik, T., and Kowalczyk, R., 2016. "Influence of management and biological factors on the parasitic invasions in the wild-spread of bloodsucking nematode Ashworthius sidemi in European bison (Bison bonasus)." International Journal of Parasitology Parasites Wildl, 29, vol. 5, pp. 286-294.

[38] Oliveira-Sequeira, T. C., Amarante, A. F., Ferrari, T. B., and Nunes, L. C., 2002. "Prevalence of intestinal parasites in dogs from Sao Paulo State, Brazil." Veterinary Parasitology, vol. 103, pp. 19-27.

[39] Lorenzini, G., Tasca, T., and De Carli, G. A., 2007. "Prevalence of intestinal parasites in dogs and cats under Veterinary care in Porto Ategre, Rio Grande do Sul, Brazil." Brazil Journal of Veterinary Research Animal Science, vol. 44, pp. 137-145.

[40] Adejinmi, J. O. and Osayomi, J. O., 2010. "Prevalence of intestinal protozoan parasites of dogs in Ibadan, south western Nigeria." Journal of Animal and Plant Science, vol. 7, pp. 783- 788. 
[41] Torres-Chable, O. M., Garcia-Herrera, R. A., Hernandez-Hernandez, M., Peralta-Torres, J. A., OjedaRobertos, N. F., Blitvich, B. J., Baak-Baak, C. M., Garcia-Rejon, J. E., and Machain-Wiliams, C. I., 2015. "Prevalence of gastrointestinal parasites in domestic dogs in Tabasco, Southeastern Mexico." Revista Brasileira de Parasitologia Veterinária, vol. 24, pp. 432-437.

[42] Kostopoulou, D., Claerebout, E., Arvanitis, D., Ligda, P., Voutzourakis, N., Casaert, S., and Sotiraki, S., 2017. "Abundance, zoonotic potential and risk factors of intestinal parasitism amongst dog and cat populations: The scenario of Crete, Greece." Parasites and Vectors, vol. 10, p. 43.

[43] European Scientific Counsel Companion Animal Parasites (ESCCAP, 2017. "ESCCAP Guideliene 01 third edition July $2017 \quad$ - Worm control in dogs and cats." Available: http://www.esccap.org/uploads/docs/0x0o7jda_ESCCAP_Guideline_01_Third_Edition_July_2017.pdf 